\section{RMD Open}

Rheumatic \&

Musculoskeletal Diseases

\title{
Health-related quality of life and disability in adults with juvenile idiopathic arthritis: comparison with adult-onset rheumatic diseases
}

Filipa Oliveira Ramos (D) ,, ${ }^{1,2}$ Ana Rodrigues, ${ }^{3}$ Fernando Magalhaes Martins, ${ }^{4}$ Ana Teresa Melo, ${ }^{1}$ Francisca Aguiar, ${ }^{5}$ Luisa Brites, ${ }^{6}$ Soraia Azevedo, ${ }^{7}$ Ana Catarina Duarte, ${ }^{8}$ Carolina Furtado, ${ }^{9}$ Ana Filipa Mourão, ${ }^{3,10}$ Graça Sequeira, ${ }^{11}$ Inês Cunha, ${ }^{12}$ Ricardo Figueira, ${ }^{13}$ Jose Antonio Melo Gomes, ${ }^{14}$ Maria Jose Santos (D) ,2,8 Joao Eurico Fonseca ${ }^{1,2}$

To cite:

Oliveira Ramos F, Rodrigues A, Magalhaes Martins F, et al. Health-related quality of life and disability in adults with juvenile idiopathic arthritis: comparison with adult-onset rheumatic diseases. RMD Open 2021;7:e01766. doi:10.1136/ rmdopen-2021-001766

Received 9 June 2021 Accepted 3 November 2021

Check for updates

(C) Author(s) (or their employer(s)) 2021. Re-use permitted under CC BY-NC. No commercial re-use. See rights and permissions. Published by BMJ.

For numbered affiliations see end of article.

Correspondence to Dr Filipa Oliveira Ramos; filipa.o.ramos@gmail.com

\section{ABSTRACT}

Objective To compare physical disability, mental health, fatigue and health-related quality of life (HRQoL) across juvenile idiopathic arthritis (JIA) categories in adulthood and between JIA and adult-onset rheumatic diseases. Methods Cross-sectional analysis nested in a cohort of adult patients with JIA registered in the Rheumatic Diseases Portuguese Register (Reuma.pt). Physical disability (Health Assessment Questionnaire—-Disability Index), mental health symptoms (Hospital Anxiety and Depression Scale), fatigue (Functional Assessment of Chronic Illness Therapy-Fatigue Scale (FACIT-F)) and HRQoL (EuroQol-5D (EQ5D) and Short Form (SF-36)) were compared across JIA categories. Patients with polyarticular JIA and enthesis-related arthritis (ERA) JIA were compared respectively to patients with rheumatoid arthritis (RA) and spondyloarthritis (SpA), matched for gender and age, adjusted for disease duration and activity.

Results 585 adult patients with JIA were included. Comparison across JIA categories showed that persistent oligoarthritis and patients with ERA reported a higher score in EQ5D and SF-36 physical component when compared with other JIA categories.

Polyarticular JIA reported less disability and fatigue than patients with RA (median Health Assessment Questionnaire of 0.25 vs $0.63 ; p<0.001$ and median FACIT-F score 42 vs 40 ; $\mathrm{p}=0.041$ ). Polyarticular JIA had also better scores on EQ5D and all domains of SF-36, than patients with RA. Patients with ERA reported less depression and anxiety symptoms ( $0 \%$ vs $14.8 \%$; $p=0.003 \%$ and $9 \%$ vs $21.3 \% ; p=0.002$ ) and less fatigue symptoms ( 45 vs $41 ; p=0.01$ ) than patients with $\mathrm{SpA}$. Conclusion Persistent oligoarticular JIA and ERA are the JIA categories in adulthood with better HRQDL. Overall, adult polyarticular and patients with ERA JIA have lower functional impairment and better quality-of-life than patients with RA and SpA.

\section{INTRODUCTION}

The term juvenile idiopathic arthritis (JIA) is used to designate a very heterogeneous group

\section{KEY MESSAGES \\ WHAT IS ALREADY KNOWN ABOUT THIS SUBJECT? \\ $\Rightarrow$ We currently know that health-related quality of life (HRQoL) of patients with juvenile idiopathic arthritis (JIA) in adulthood is lower than for the general pop- ulation. Less is known about HRQoL of patients with JIA in adulthood compared with adult-onset rheu- matic diseases. \\ WHAT DOES THIS STUDY ADD? \\ $\Rightarrow$ This study, that compared for the first time, different patient reported outcomes regarding mental health symptoms, fatigue and HRQOL across JIA categories in adulthood and also adult patients with JIA with adult-onset rheumatic diseases, showed that adult polyarticular and patients with ERA JIA have an overall better quality of life than patients with rheu- matoid arthritis and spondyloarthritis. \\ HOW MIGHT THIS IMPACT ON CLINICAL PRACTICE OR FURTHER DEVELOPMENTS? \\ $\Rightarrow$ We believe that understanding the way these juve- nile diseases impact the mental health and HRQoL in adulthood could help to develop strategies to enable multidisciplinary responses in order to improve cop- ing and general health promotion of these patients. \\ $\Rightarrow$ In our view these results will be of interest to both paediatric and adult rheumatologists who are in- volved in the clinical care of patients with JIA.}

of chronic inflammatory diseases with onset before 16 years old that actually correspond to distinct diseases with different prognosis. ${ }^{1}$ The course of these diseases is highly variable but several studies estimate that $37 \%-63 \%$ of the adults who have had a diagnosis of JIA in childhood maintain active disease. ${ }^{2-6}$ For 
these patients, as well as for the patients that achieve disease remission but experience damage caused by JIA or medication side effects, the disease has impact on their health-related outcomes. ${ }^{5}$ Even though efforts have been made to determine predictors of long-term outcomes regarding physical disability, psychological and healthrelated quality of life (HRQoL) in JIA, ${ }^{478}$ the global burden of the disease is still not accurately established.

Patient-reported outcomes (PROs) are crucial for patient-centred healthcare as they can directly measure several dimensions of patient's health. ${ }^{9}$ Despite the common use of PROs in adult patients with JIA in clinical practice, we still do not have a complete knowledge of these outcomes in every dimensions. What we currently know is that HRQoL of patients with JIA in adulthood is lower than for the general population, ${ }^{3}{ }^{5} 10$ similarly to several adult-onset rheumatic diseases. ${ }^{11} 12$ However less is known about HRQoL of adult patients with JIA compared with patients with other rheumatic diseases with adult onset. ${ }^{13}$ The same is true for the long-term psychological effects of JIA in adulthood, with significant morbidity being reported ${ }^{14}$ but without substantial data that compares it with adult-onset rheumatic diseases. Of note, we have previously shown that most adult polyarticular JIA and enthesis-related arthritis (ERA) patients fulfil classification criteria for rheumatoid arthritis (RA) and spondyloarthritis (SpA) and maintain disease activity and functional impairment in adulthood. ${ }^{4}$

The aims of this study were to evaluate PROs (namely physical disability, mental health, fatigue and HRQoL) across different JIA categories in adulthood, compare these PROs between polyarticular adult patients with JIA and patients with RA and between adult patients with ERA and patients with adult-onset SpA.

\section{METHODS}

\section{Study design and patient selection}

This is a cross-sectional analysis nested in a cohort study with the following inclusion criteria: patients with JIA according to the 2001 revised International League of Associations for Rheumatology (ILAR) criteria, ${ }^{1}$ registered in the Rheumatic Diseases Portuguese Register (Reuma.pt) ${ }^{15}$ that at the time of data extraction (December 2019) were older than 18 years old, had a disease duration greater than 5 years and available data in adulthood.

Reuma.pt was developed by the Portuguese Society of Rheumatology, became active in June 2008 and includes patients with JIA, RA, SpA and several other rheumatic diseases. Specifically, 1955 patients with JIA have been registered so far in Reuma.pt. ${ }^{16}$

At the time of this analysis, a total of 650 adult patients with JIA were registered. Thirty of them were excluded due to the lack of data registered in adulthood. Of the 620 patients eligible for this study only 585 had complete data registered regarding ILAR category at onset and were included (figure 1). From these 585 patients, 279

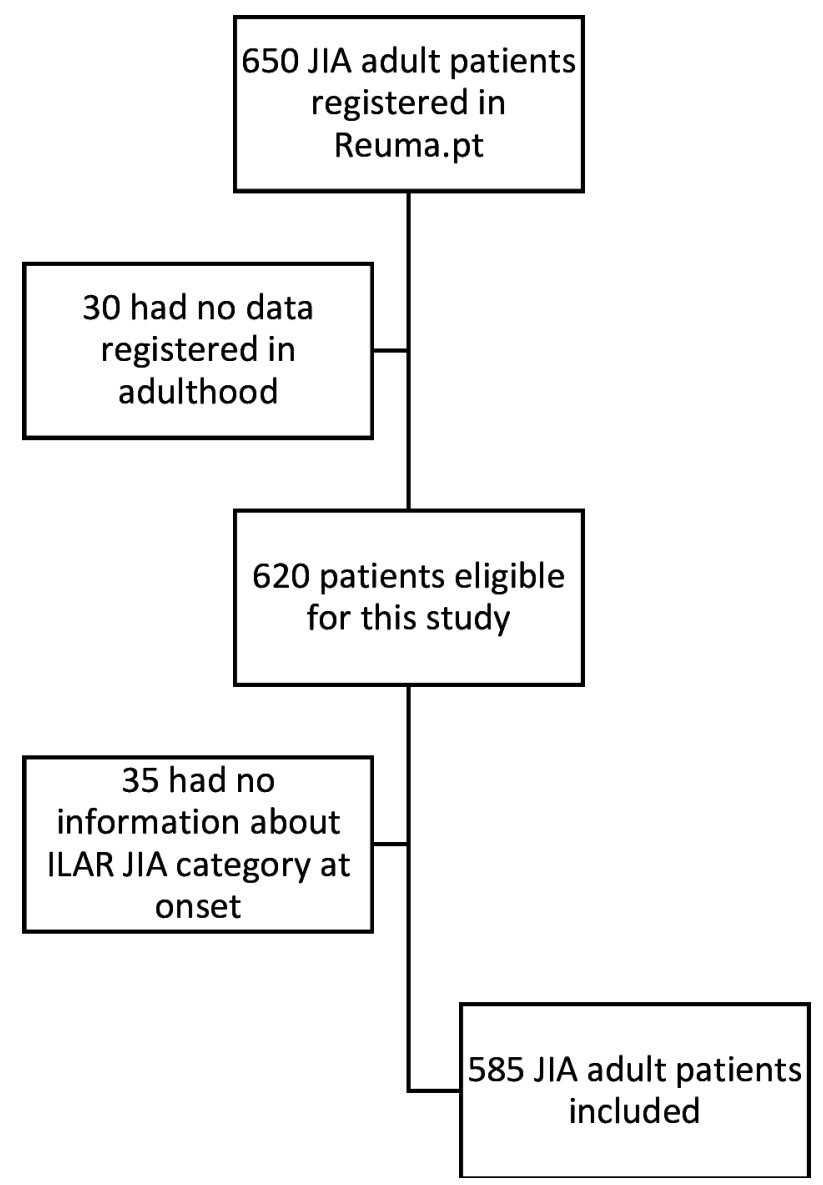

Figure 1 Disposition of adult patients with JIA registered in Reuma.pt eligible for this study. ILAR, International League of Associations for Rheumatology; JIA, juvenile idiopathic arthritis.

patients were registered in childhood and 306 patients were introduced in Reuma.pt already in adulthood and classified retrospectively according to the ILAR classification. Data before 2008 was registered retrospectively and prospectively thereafter.

Patients with polyarticular JIA course (extended oligoarthritis, rheumatoid factor (RF) negative and RF positive polyarthritis) and with ERA were compared, respectively, to the same number of controls constituted by patients with adult-onset RA and SpA, registered in Reuma.pt, matched for gender and age group. In order to achieve this, the 9046 RA and 4827 patients with adultonset SpA registered in Reuma.pt up to the date of data capture, were grouped according to their gender and age group (18-39 years old; 40-59 years old and $\geq 60$ years old) and then randomised in order to match by gender and age group the polyarticular JIA course and patients with ERA, respectively.

Registry of patient data in Reuma.pt occurred after signed informed consent was obtained. This study was approved by the scientific committee of Reuma.pt and by the ethics committee of Lisbon Academic Medical Centre. Reuma.pt was approved by the National Data Protection Authority and by local ethics committees 


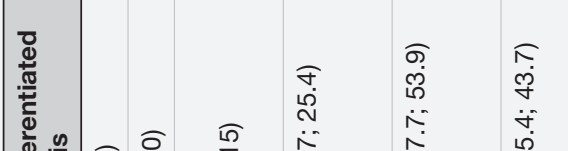

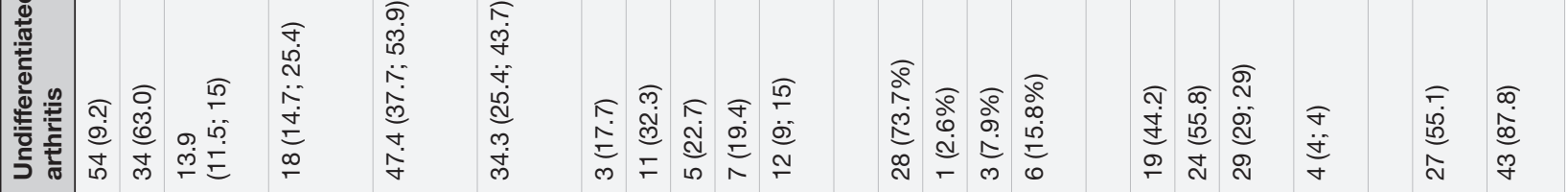

0.

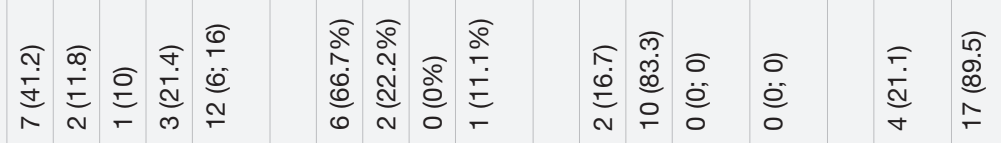

ఫ

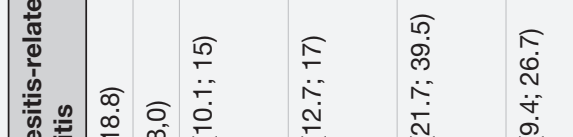

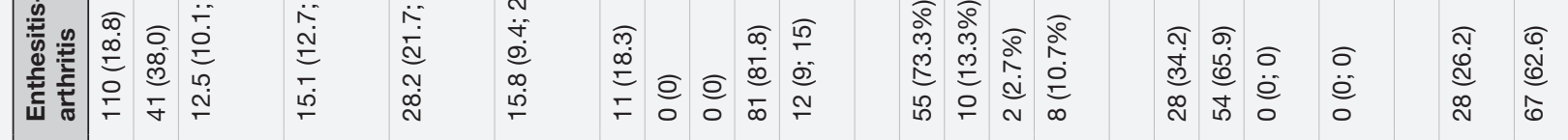

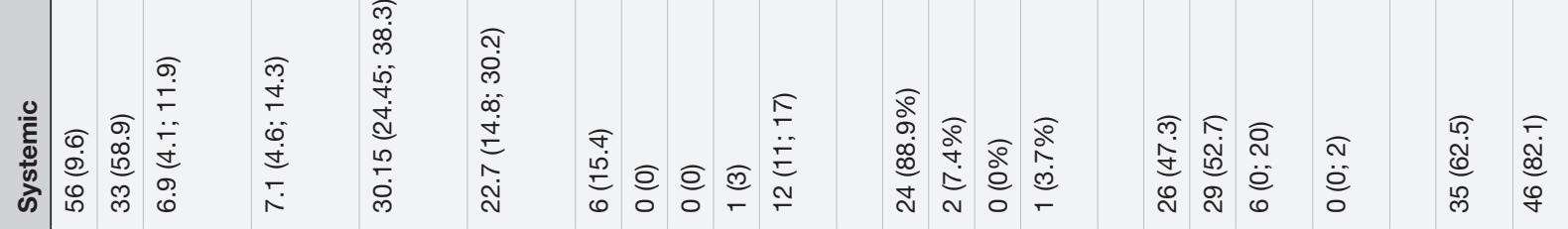

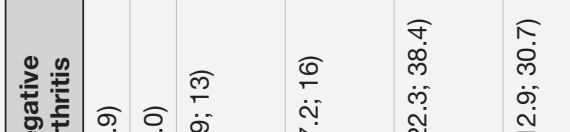

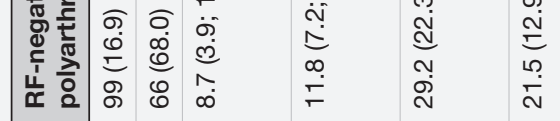

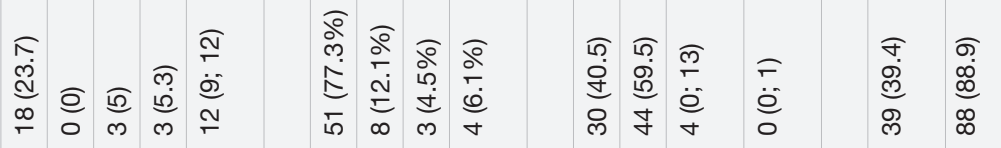

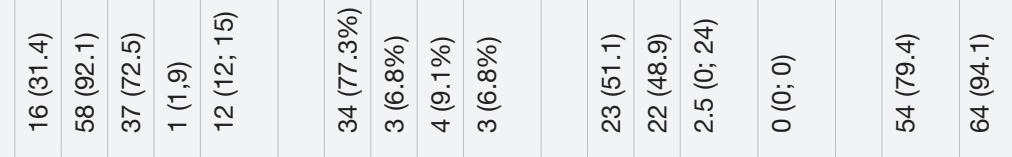

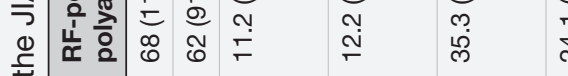

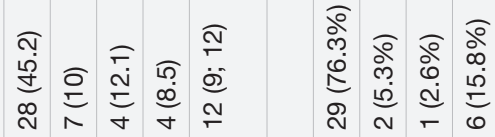

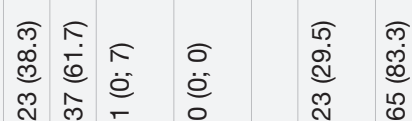

离

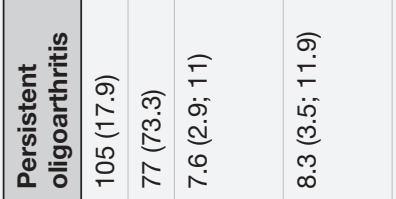

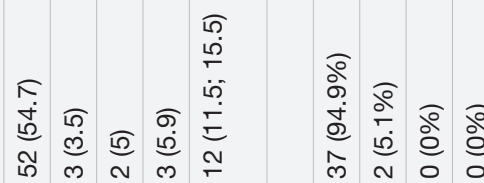

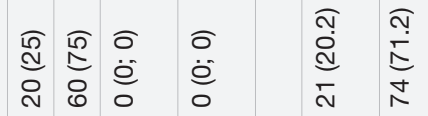

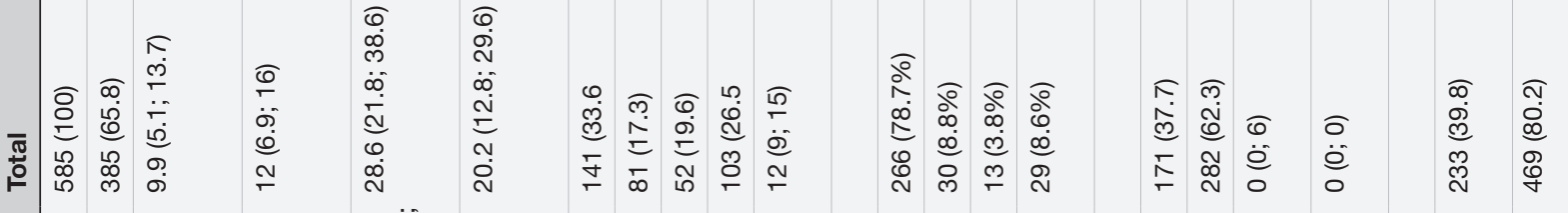

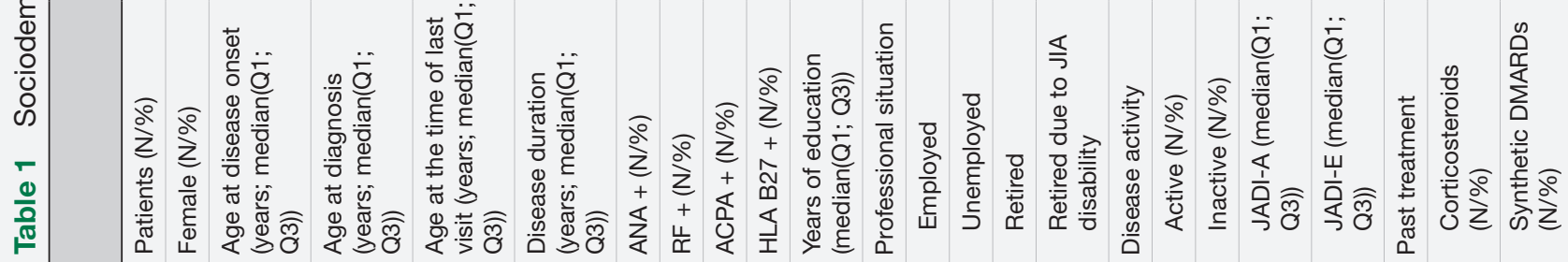




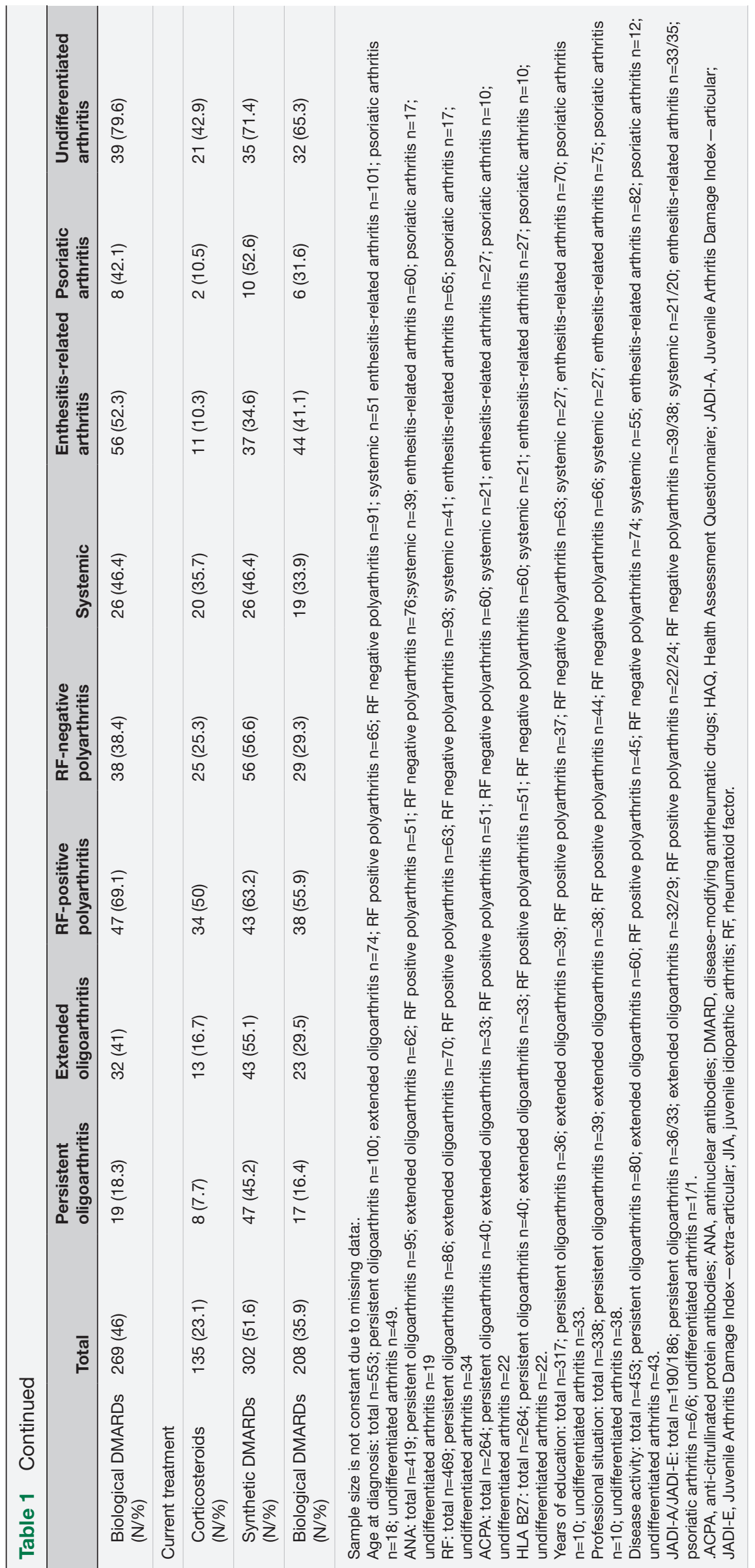

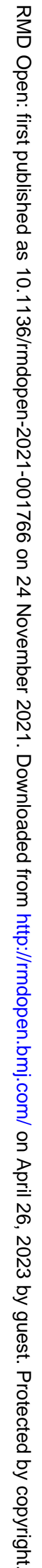


of the participating centres. The study was conducted according to the Declaration of Helsinki.

\section{Clinical data collection}

The following information registered at the time of patient's last visit available at the moment of data exportation (December 2019) was obtained: sex, ethnicity, age at last visit, years of education, employment status (employed, unemployed, retired and early retirement due to JIA induced disability as certified by a board of physicians), ILAR category at onset, age at disease onset, disease duration (years), presence of RF, anti-citrullinated protein antibodies (ACPA), antinuclear antibodies (considered positive if titres $\geq 1 / 160$ ) and human leukocyte antigen B27 (HLA B27), number of active joints, patient and physician's global assessment of disease activity $(0-10)$, back pain $(0-10)$, morning stiffness intensity $(0-10)$, erythrocyte sedimentation rate (ESR, mm/ first hour) and $\mathrm{C}$ reactive protein level (CRP, mg/ dL), extra-articular manifestations, Health Assessment Questionnaire (HAQ) score, Juvenile Arthritis Damage Index (JADI) score, current and previous therapy with corticosteroids, disease-modifying antirheumatic drugs (DMARD) and biological therapy.

In the Reuma.pt JIA protocol there is a field asking the physician to check if the adult patient fulfils classification criteria for any of the following adult rheumatic diseases: RA; ankylosing spondylitis (AS); psoriatic arthritis (PsA); undifferentiated spondyloarthritis; adult-onset Still disease (AOSD); nonclassifiable. Data registered in this Reuma.pt field were also exported.

Juvenile Arthritis Disease Activity Score,${ }^{17}$ shows limitations for the assessment of adults with JIA, particularly those with predominant axial disease. For that reason we opted to apply disease activity scores specific for adult-onset rheumatic diseases as described in Oliveira-Ramos et al. ${ }^{4}$ Patients were classified as having inactive disease based on cut-offs defined for each index: Disease Activity Score (DAS) $28<2.6^{18-20}$ for patients who could be classified as RA; DAS 44, and DAS $44<1.6^{21} 22$ for PsA and peripheral patients with SpA; AS DAS $<1.3^{23}$ for patients who fulfil classification criteria now in adulthood for AS. Patients classified as AOSD or with non-classifiable adult rheumatic disease were considered to have inactive disease if they had: no active arthritis; no fever, rash, serositis, splenomegaly or generalised lymphadenopathy attributable to JIA; no active uveitis; normal ESR and/or CRP; a physician's global assessment of disease activity rated at the best score possible. ${ }^{24}$ The disease activity was measured at the same time of PROs' fulfilment.

In the absence of a validated score for evaluation of damage in adults with JIA, we opted to use JADI, as a more comprehensive way of assessing articular damage (JADI-A) and extra-articular damage (JADI-E) ${ }^{25}$

\section{Patient-reported outcomes variables}

In every clinical visit registered in Reuma.pt, patients are asked to fulfil PROs, with a minimum frequency of every 6 months for the assessment of functional status and every year for questionnaires assessing HRQoL. The functional status was measured by Health Assessment Questionnaire-Disability Index,${ }^{26}$ obtained at the last visit registered. For the purpose of this analysis, mild disability was considered for HAQ scores $>0$ and $\leq 0.5$, moderate disability $>0.5$ and $\leq 1.5$ and severe disability $>1.5 .^{27}$

HRQoL was assessed using the 3-level version of EuroQol-5D (EQ5D) ${ }^{28}$ and Medical Outcomes Study 36-item Short Form (SF-36) ${ }^{29}$

In order to evaluate fatigue, the results of the Functional Assessment of Chronic Illness Therapy-Fatigue Scale $^{30}$ were obtained

Anxiety and depression symptoms of our study population were measured using results from the Hospital Anxiety and Depression Scale (HADS). ${ }^{31}$ Scores between 0 and 7 represent 'no case'; 8-10 indicate 'possible case' and 11-21 suggest a 'probable case of anxiety/depression'. ${ }^{32}$ We considered the presence of symptoms of anxiety if HADS-A $\geq 11$ and presence of symptoms of depression if HADS-D $\geq 11$. ${ }^{31}$

\section{Statistical analysis}

Categorical data were presented by its absolute and relative frequency while continuous data were presented using the median and quartiles of their distribution due to the lack of normality, evaluated by the Shapiro-Wilk test. Considering this, non-parametric testes were used to compare groups concerning continuous data, namely the Kruskal-Wallis test with pairwise comparisons adjusted for multiple comparisons whenever the categories of JIA were being compared. When statistically significant, these pairwise comparisons were then performed considering a reference category (persistent oligoarthritis JIA) using Benjamini-Hochberg correction with a false discovery rate of $20 \%$, applied to $p$ values of multiple comparisons.

To compare PROs between polyarticular course patients with JIA and RA and between ERA in adulthood and SpA, concerning continuous data the Mann-Whitney $\mathrm{U}$ test was used. For categorical data, the Fisher's exact test was applied.

When the differences regarding disease duration and disease activity between polyarticular course patients with JIA and RA and ERA in adulthood and SpA were significant we applied analysis of covariance (ANCOVA) or two-way analysis of variance (ANOVA) models in order to adjust the results for these variables. Possible associations between age of the patient's groups and PROs results were analysed using Spearman correlation.

Missing data were interpreted as random missing data. Analysis was performed in IBM SPSS Statistics, V.26, at a $5 \%$ significance level. 


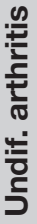

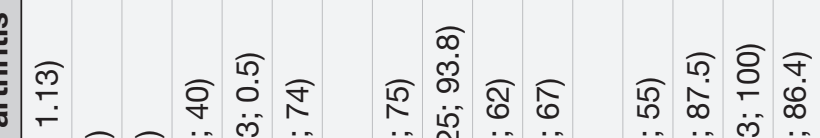

苛

5 ᄃी

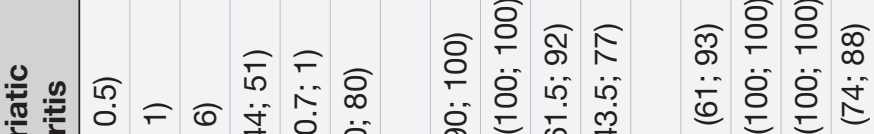

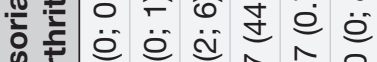
Q̊

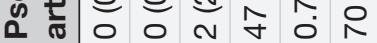

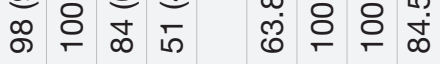

尝

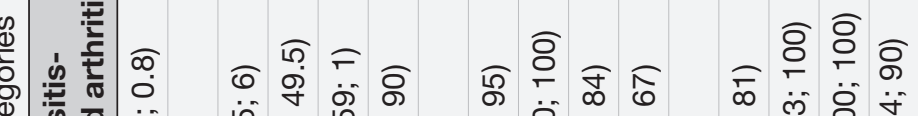

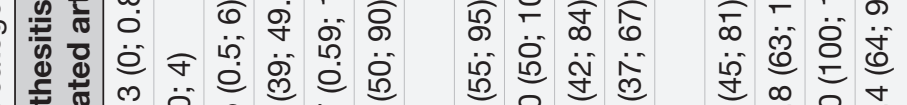

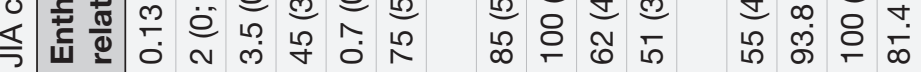

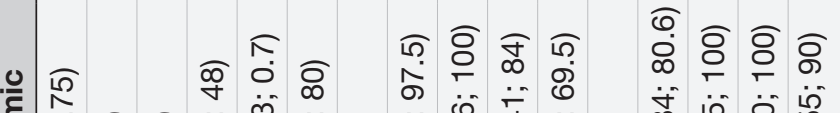

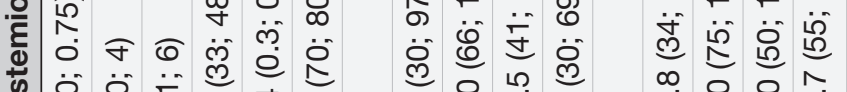

के

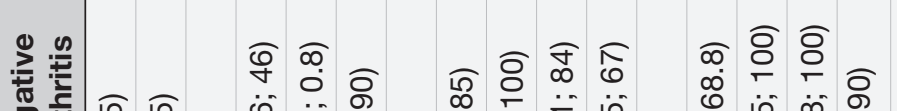

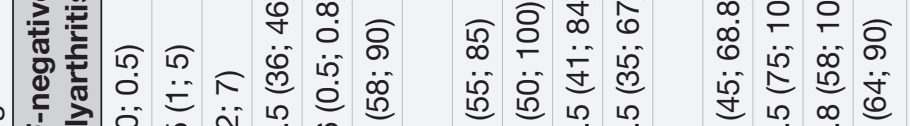

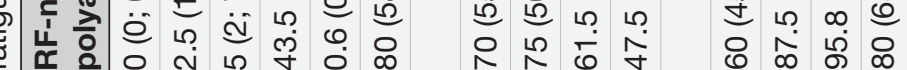

: $\frac{\sqrt{2}}{x}$

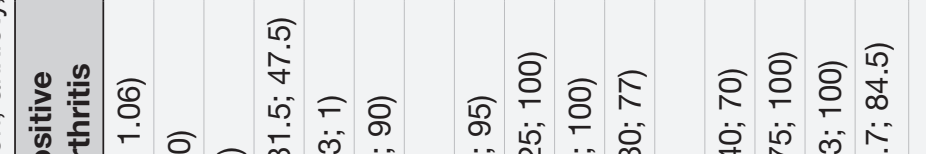

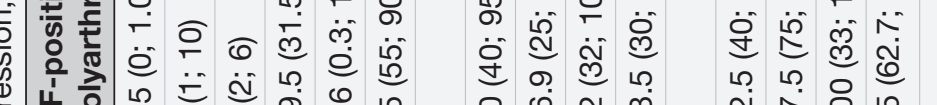

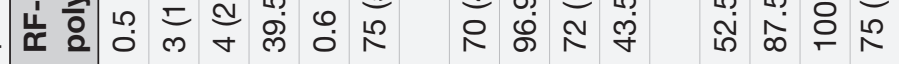

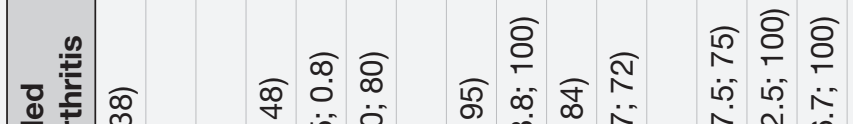

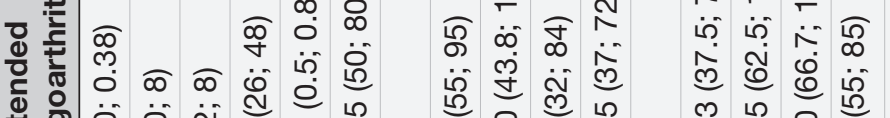

잉ำ

œ.

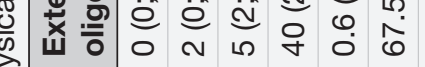

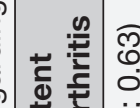

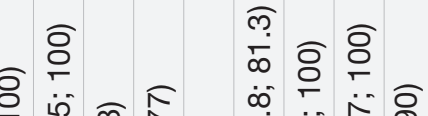

ช்

ò

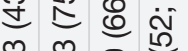

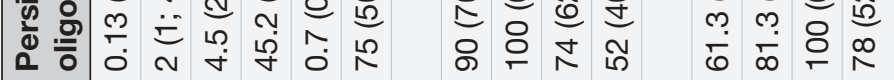

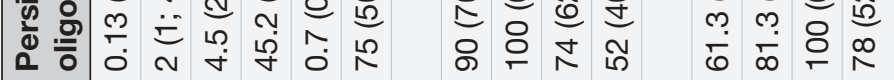

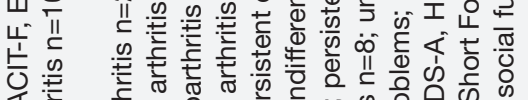

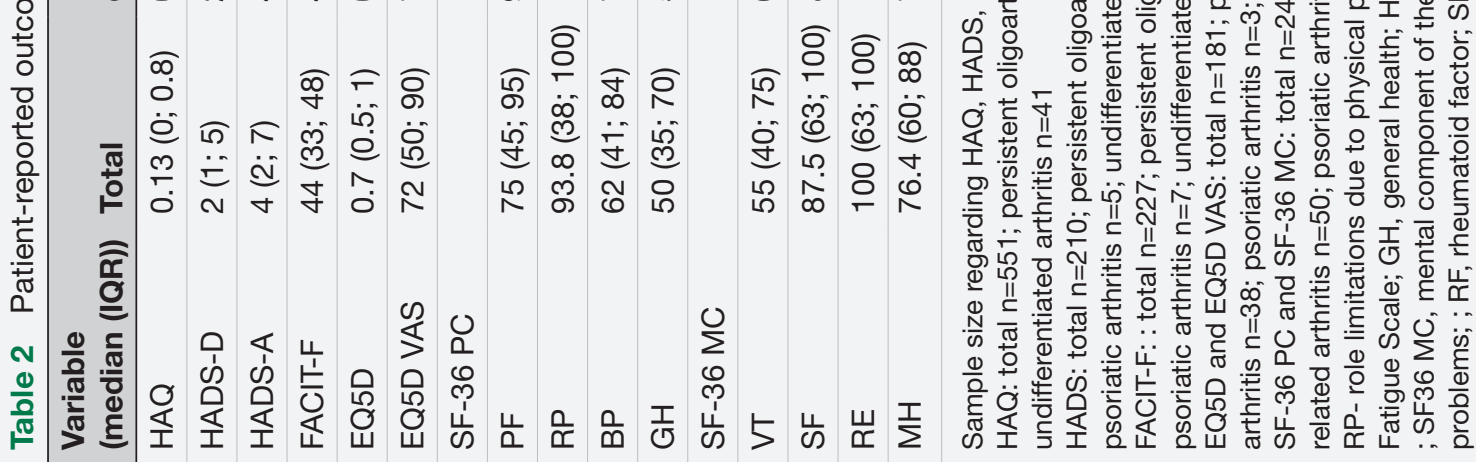

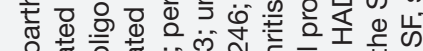

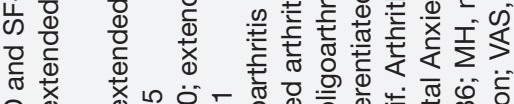

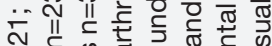

II. $\frac{\infty}{2}$ 更

ब

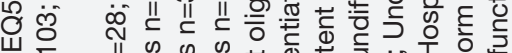

잉

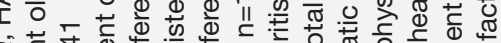

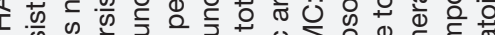

政

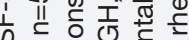

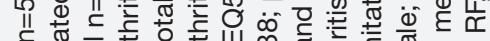
क व

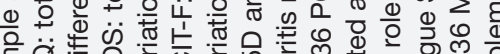




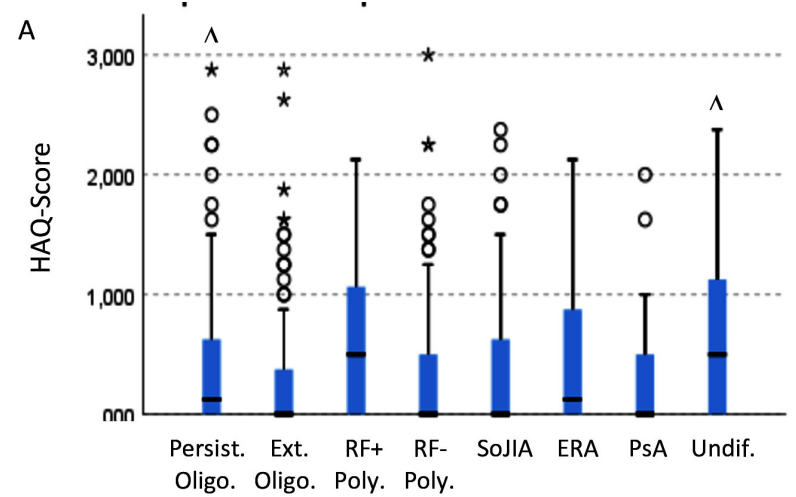

B

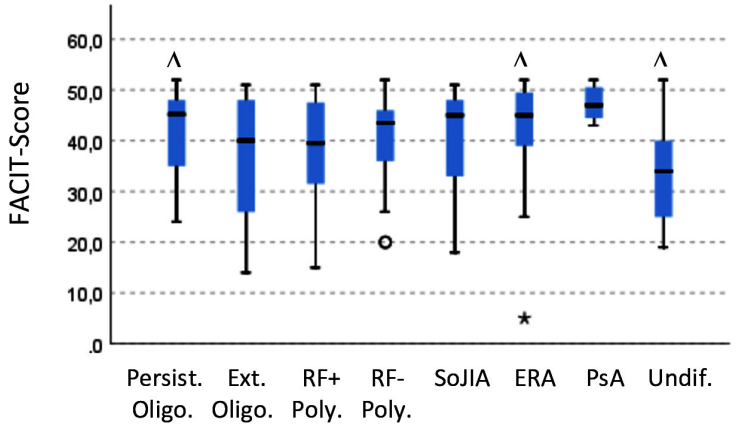

c

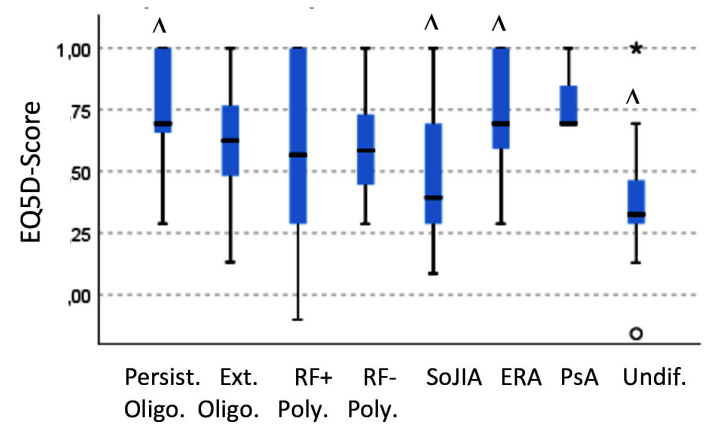

Figure 2 Patients' physical disability (Health Assessment Questionnaire (HAQ) score) according to JIA category. (B). Fatigue (Functional Assessment of Chronic Illness Therapy, Fatigue Scale (FACIT-F) score) according to JIA category. (C). Health-related quality of life (EuroQol-5D (EQ5D) score) according JIA category. Bars show the lower and upper quartiles; error bars show the range excluding outliers; horizontal lines within bars show the median; circles show outliers; asterisks show extreme values, triangles show significant pairwise comparisons $(p<0.05)$. ERA, enthesitis-related arthritis; Ext. oligo, extended oligoarthritis; JIA, juvenile idiopathic arthritis; Persist. oligo, persistent oligoarthritis; PsA, psoriatic arthritis; RF, rheumatoid factor; RF+ Poly., RF negative polyarthritis; RF- Poly., RF negative polyarthritis; SoJIA, systemic onset JIA; Undif., undifferentiated arthritis.

\section{RESULTS}

Patient characteristics

A total of 585 patients with JIA were included in the study, whose main demographic and clinical features are shown in table 1.

The median age at the last registered visit was 28.6 years (1-3 quartile: 21.8-38.6; range: 18-73) and median disease duration was 20.2 years (1-3 quartile: 12.8-29.6; range: $6-57)$. Most of the patients $(85 \%)$ had disease for more than 10 years and $25 \%$ exceeded 30 years. JIA categories with polyarticular involvement and ERA were the most prevalent ones. Missing values of RF in RF positive polyarticular patients with JIA relate to the absence of the entrance of the value in Reuma.pt but the attending physician have classified the patient based on the RF result registered in the hospital clinical record. RF positive polyarticular patients with JIA with a negative RF result registered were all ACPA positive.

This was a predominantly professionally active population $(78.6 \%$ of the patients employed), with a median 12 years of education.

Thirty-eight per cent of the studied patients still had active disease, $51.6 \%$ were on a synthetic DMARD and $35.9 \%$ on a biological DMARD. Only $35.8 \%$ of the patients with inactive disease were off medication. $66.9 \%$ of the patients had no or mild HAQ disability and $8.7 \%$ severe disability.

PROs - physical disability, mental health symptoms, fatigue and HRQOL-across JIA categories

Results of HAQ, anxiety and depression scores according to HADS, FACIT, EQ5D and SF-36 in all domains, according to JIA ILAR categories are shown in table 2. Of the 585 patients with JIA included in the study, at the last visit registered, 551 had a registered HAQ, 210 HADS, 227 FACIT-F, 181 EQ5D and 246 SF-36.

Out of the 13 analysed PROs (HAQ, HADS depression and anxiety, FACIT-F, EQ5D and 8 domains of SF-36), 7 showed statistically significant differences across JIA categories by Kruskal-Wallis test. These included physical disability (HAQ), fatigue (FACIT-F) and HRQoL (EQ5D and the SF-36 domains of physical function, role limitations due to physical problems, intensity and discomfort caused by pain and social functioning).

Relative to persistent oligoarthritis, patients with undifferentiated arthritis had higher levels of physical disability $(\mathrm{p}=0.040)$ and fatigue $(\mathrm{p}=0.009)$, worse scores in EQ5D $(p<0.001)$ and in the SF-36 domains of physical function $(\mathrm{p}<0.001)$, role limitations due to physical problems $(p=0.001)$, intensity and discomfort caused by pain $(\mathrm{p}<0.001)$ and social functioning $(\mathrm{p}=0.001)$.

As persistent oligoarthritis patients, patients with ERA had less fatigue reports than other categories of patients with JIA (figure 2), with a relevant difference when compared with patients with undifferentiated arthritis (median FACIT-F score in patients with ERA $45(39 ; 49.5)$ vs $34(25 ; 40)$ in patients with undifferentiated arthritis; $\mathrm{p}=0.045)$. Patients with ERA had also better results regarding HRQoL, with higher median EQ5D scores when compared with with systemic onset JIA (SoJIA) $(0.69(0.59 ; 1)$ in ERA vs $0.39(0.29 ; 0.69)$ in SoJIA; $\mathrm{p}=0.029$ ). 
Table 3 Sociodemographic, disease-related characteristics, physical disability, levels of depression, anxiety, fatigue and quality of life of the adult patients with JIA and patients with adult-onset rheumatic diseases

\begin{tabular}{|c|c|c|c|c|c|c|}
\hline Variables & $\begin{array}{l}\text { Patients with JIA } \\
\text { with polyarticular } \\
\text { involvement ( } n=245)\end{array}$ & $\begin{array}{l}\text { Control group of } \\
\text { patients with RA } \\
(n=245)\end{array}$ & $P$ value & $\begin{array}{l}\text { Patients with ERA } \\
\text { and JIA }(n=110)\end{array}$ & $\begin{array}{l}\text { Control group of } \\
\text { patients with SpA } \\
(n=110)\end{array}$ & $P$ value \\
\hline Female, n (\%) & $183(74.7)$ & $183(74.7)$ & 1.000 & 41 (38.3) & $42(38.2)$ & 1.000 \\
\hline \multicolumn{7}{|l|}{$\begin{array}{l}\text { Age at the time of last registered } \\
\text { visit, } n(\%)\end{array}$} \\
\hline $18-39$ years old & $156(62.4)$ & $156(62.4)$ & 0.569 & $76(69)$ & $76(69)$ & 0.155 \\
\hline $40-59$ years old & $76(31.0)$ & $76(31.0)$ & 0.095 & $27(24.5)$ & $27(24.5)$ & 0.426 \\
\hline$\geq 60$ years old & $13(5.3)$ & $13(5.3)$ & 0.561 & $7(6.4)$ & $7(6.4)$ & 0.147 \\
\hline $\begin{array}{l}\text { Disease duration, years (median } \\
\text { (Q1; Q3)) }\end{array}$ & $21.59(14.79 ; 31.18)$ & $12.36(8.52 ; 16.67)$ & $<0.001$ & $15.76(9.46 ; 26.69)$ & $15.07(10.36 ; 19.89)$ & 0.414 \\
\hline $\begin{array}{l}\text { Years of education (median (Q1; } \\
\text { Q3)) }\end{array}$ & $12(9 ; 14)$ & $12(7 ; 15)$ & 0.251 & $12(9 ; 15)$ & $12(9 ; 12)$ & 0.591 \\
\hline \multicolumn{7}{|l|}{$\begin{array}{l}\text { Current professional situation, } \\
\mathrm{n}(\%)\end{array}$} \\
\hline Employed & $114(77)$ & $143(81.7)$ & 0.728 & 55 (73.3) & $76(82.6)$ & 0.287 \\
\hline Retired & $8(5.4)$ & $7(4)$ & 0.621 & $2(2.7)$ & $4(4.3)$ & 0.568 \\
\hline Retired by disability & $13(8.8)$ & $11(6.3)$ & 0.598 & $8(10.7)$ & $4(4.3)$ & 0.082 \\
\hline Unemployed & $13(8.8)$ & $14(8)$ & 0.432 & $10(13.3)$ & $8(8.7)$ & 0.537 \\
\hline Active disease, $\mathrm{n}(\%)$ & $76(42.5)$ & 99 (41.5) & 0.787 & $28(34.1)$ & $63(59.4)$ & $<0.001$ \\
\hline HAQ score (median (Q1; Q3)) & $0.25(0 ; 1)$ & $0.63(0.13 ; 1.13)$ & $<0.001^{*}$ & $0(0 ; 0.44)$ & $0.75(0 ; 1.5)$ & $0.025+$ \\
\hline $\begin{array}{l}\text { HADS-depression symptoms, } \\
\mathrm{n}(\%)\end{array}$ & $7(8)$ & $8(9.5)$ & $0.075^{\star}$ & $0(0)$ & $9(14.8)$ & $0.003 \dagger$ \\
\hline HADS - anxiety symptoms, n (\%) & $8(9.2)$ & $16(19)$ & $0.080^{*}$ & $4(9)$ & $13(21.3)$ & $0.002 \dagger$ \\
\hline FACIT-F (median (Q1; Q3)) & $42(33.5 ; 47)$ & $40(29 ; 47.5)$ & $0.041^{*}$ & $45(39 ; 49.5)$ & $41(29 ; 46)$ & $0.01 \dagger$ \\
\hline EQ5D (median (Q1; Q3)) & $0.62(0.4 ; 0.7)$ & $0.58(0.45 ; 0.77)$ & $<0.001^{*}$ & $0.69(0.59 ; 1)$ & $0.66(0.45 ; 0.7)$ & $0.155 \dagger$ \\
\hline EQ5D VAS (median (Q1; Q3)) & $79(50 ; 90)$ & $15(1 ; 37)$ & $<0.001^{*}$ & $75(50 ; 90)$ & $20(5 ; 48)$ & $0.155 \dagger$ \\
\hline \multicolumn{7}{|l|}{ SF-36 PC } \\
\hline PF (median (Q1; Q3)) & $75(50 ; 90)$ & $72.22(45 ; 95)$ & $<0.001^{*}$ & $85(55 ; 95)$ & $80(50 ; 90)$ & $0.690 \dagger$ \\
\hline RP (median (Q1; Q3)) & $81.25(25 ; 100)$ & $75(25 ; 100)$ & $<0.001^{*}$ & $100(50 ; 100)$ & $75(25 ; 100)$ & $0.621 \dagger$ \\
\hline BP (median (Q1; Q3)) & $62(41 ; 84)$ & $62(41 ; 79)$ & $<0.001^{*}$ & $62(42 ; 84)$ & $62(41 ; 74)$ & $0.378 \dagger$ \\
\hline GH (median (Q1; Q3)) & $50(35 ; 72)$ & $43.5(30 ; 61)$ & $<0.001^{*}$ & $51(37 ; 67)$ & $45(30 ; 57)$ & $0.989 \dagger$ \\
\hline \multicolumn{7}{|l|}{ SF-36 MC } \\
\hline VT (median (Q1; Q3)) & $56.25(40 ; 75)$ & $50(47.5 ; 55)$ & $<0.001^{*}$ & $55(45 ; 81.25)$ & $50(45 ; 62.5)$ & $0.523 \dagger$ \\
\hline SF (median (Q1; Q3)) & $87.5(62.5 ; 100)$ & $62.5(39.5 ; 100)$ & $<0.001^{*}$ & $93.75(62.5 ; 100)$ & $75(50 ; 100)$ & $0.519 \dagger$ \\
\hline RE (median (Q1; Q3)) & $100(58.33 ; 100)$ & $100(33.33 ; 100)$ & $<0.001^{*}$ & $100(100 ; 100)$ & 91.67 (58.33; 100) & $0.527 \dagger$ \\
\hline MH (median (Q1; Q3)) & $76(61.4 ; 88)$ & $69(51.7 ; 86.5)$ & $<0.001^{*}$ & $81.4(64 ; 90)$ & $72(53.5 ; 82.7)$ & $0.795+$ \\
\hline
\end{tabular}

Sample size regarding HAQ, HADS, FACIT-F, EQ5D and SF-36 and other variables is not constant due to:

Years of education: JIA with polyarticular involvement $n=139$; control group of patients with RA $n=150 ;$ ERA JIA $n=70$; control group of patients with SpA $n=69$.

Current professional situation: JIA with polyarticular involvement $n=148$; control group of patients with RA $n=143$; ERA JIA $n=75$; control group of patients with SpA $\mathrm{n}=76$.

Active disease: JIA with polyarticular involvement $n=179$; control group of patients with RA $n=238$; ERA JIA $n=82$; control group of patients with SpA $n=110$.

HAQ score: JIA with polyarticular involvement $n=242$; control group of patients with RA $n=199$; ERA JIA $n=88$; control group of patients with SpA $n=9$.

HADS: JIA with polyarticular involvement $n=87$; control group of patients with RA $n=84$; ERA JIA $n=44$; control group of patients with SpA $n=61$

FACIT-F: JIA with polyarticular involvement $n=96$; control group of patients with RA $n=84$; ERA JIA $n=48$; control group of patients with SpA $n=65$

EQ5Ds score and VAS: JIA with polyarticular involvement $n=77$; control group of patients with RA $n=108$; ERA JIA $n=38$; control group of patients with SpA $n=82$.

SF-36: JIA with polyarticular involvement $n=99$; control group of patients with $R A n=160$; ERA JIA $n=50$; control group of patients with SpA $n=101$.

*After adjustment for disease duration.

†After adjustment for disease activity.

. BP, intensity and discomfort caused by pain; EQ5D, EuroQol-5D; ERA, enthesitis-related arthritis; FACIT-F, Chronic IIIness Therapy, Fatigue Scale; GH, general health; HADS-A, Hospital Anxiety and Depression Scale-anxiety; HADS-D, Hospital Anxiety and Depression Scale-depression; HAQ, Health Assessment

Questionnaire; JIA, juvenile idiopathic arthritis; SF36 MC, mental component of the Short Form 36; MH, mental health; ; SF36 PC, physical component of the Short

Form 36; PF, physical function; RA, rheumatoid arthritis ; RE, role limitations due to emotional problems; RP, role limitations due to physical problems; SF, social

function; SF36, Medical Outcomes Study 36-item Short Form; SpA, spondyloarthritis; VAS, Visual Analogue Scale; VT, vitality.

Patients with persistent oligoarthritis and ERA had also significantly better scores in the physical component of the SF-36, when compared with patients with undifferentiated arthritis regarding physical function (90 $(70 ; 100)$ vs $40(20 ; 75) ; \mathrm{p}<0.001$ and $0.69(0.59 ; 1)$ vs 40 $(20 ; 75) ; \mathrm{p}=0.003$, respectively), role limitations due to 
physical problems $(100(62.5 ; 100)$ vs $37.5(25 ; 93.75)$; $\mathrm{p}=0.014$ and $100(50 ; 100)$ vs $37.5(25 ; 93.75) ; \mathrm{p}=0.018$, respectively) and intensity and discomfort caused by pain $(74(62 ; 84)$ vs $51(31 ; 62) ; \mathrm{p}<0.001$ and $62(42 ; 84)$ vs $51(31 ; 62) ; \mathrm{p}=0.041)$. Patients with undifferentiated arthritis had also worse scores in physical function and role limitations due to physical problems domains when compared with patients with PsA $(40(20 ; 75)$ vs 97.5 $(90 ; 100) ; p=0.001$ and 37.5 (25; 93.75$) ; 100$ (100; 100); $\mathrm{p}=0.011$, respectively).

Of all patients with JIA, $10.5 \%$ and $4.8 \%$, respectively, presented anxiety and depression symptoms (HADS score $\geq 11$ ), however we found no differences regarding anxiety and depression levels between JIA categories.

\section{Comparison of PROs (functional status, mental health} symptoms, fatigue and HRQoL) between patients with JIA and adult-onset rheumatic diseases

For the group of patients with JIA with polyarticular involvement and ERA, respectively, 245 RA controls and $110 \mathrm{SpA}$ controls matched for sex and group ages, were selected from Reuma.pt. The demographic and clinical characteristics of the patients with JIA and controls are summarised in table 3 . Sixty-three per cent and $51.4 \%$ of patients with RA and $32.3 \%$ and $44.7 \%$ of the adult-onset SpA were on a synthetic or biological DMARD, respectively.

After adjustment for disease duration, we found less disability in polyarticular patients with JIA when compared with patients with RA (median HAQ of 0.25 $(0 ; 1)$ in polyarticular course JIA vs $0.63(0.13 ; 1.13)$ in RA; $\mathrm{p}<0.001)$. Regarding depression and anxiety symptoms in these two groups of patients we did not find any differences. On the contrary we found that polyarticular course patients with JIA had better results than patients with RA regarding fatigue (FACIT-F scores $42(33.5 ; 47)$ vs $40(29 ; 47.5) ; p=0.041)$ and HRQoL, with better scores on EQ5D, both in self-reported problems and perceived health through Visual Analogue Scale (VAS) and all domains of SF-36 (table 3).

Regarding patients with ERA and SpA, after adjustment for disease activity, we found that patients with ERA had less disability (median HAQ of $0(0 ; 0.44)$ in ERA vs 0.75 $(0 ; 1.5)$ in patients with $\mathrm{SpA} ; \mathrm{p}=0.025)$, less depression and anxiety symptoms $(0 \%$ vs $14.8 \% ; \mathrm{p}=0.003 \%$ and $9 \%$ vs $21.3 \% ; \mathrm{p}=0.002)$ and less fatigue symptoms (45 (39; $49.5)$ vs $41(29 ; 46) ; p=0.01)$ than patients with $\mathrm{SpA}$. The differences in EQ5D and SF-36 scores between patients with ERA and SpA, after adjustment for disease activity, were not found to be significant (table 3 ).

\section{DISCUSSION}

To the best of our knowledge, this is the only study of long-term follow-up of patients with JIA comparing mental health symptoms, fatigue and HRQoL across JIA categories and with adult-onset rheumatic diseases. This adult JIA population with a median disease duration of
20.2 years ( $25 \%$ exceeding 30 years of disease duration) had a predominance of polyarticular and ERA categories, which reflects the JIA population that prevail in adult Rheumatology care. Most of these patients were still on a synthetical or biological DMARD and $38 \%$ had active disease, which is in line with the disease activity profile depicted in other long-term studies. Selvaag et al reported that $41 \%$ of the patients with JIA maintained disease activity after 30 years and other studies reported active disease in $37 \%-46 \%$ of the patients. ${ }^{6}{ }^{63}$ Disease status varied according to JIA categories, with inactive disease most often seen in patients with persistent oligoarticular JIA and least often seen in RF-positive polyarticular JIA, as shown in previous studies. ${ }^{63} 34$

The degree of disability in our patients mirrored the ones found in other recent studies of adult outcomes in JIA. A decade ago JIA outcome studies described poorer functional outcomes, as in the Foster et al, ${ }^{3}$ study that found a median HAQ of $1.13(0 ; 3)$ or the Packman et al $^{14}$, that depicted severe disability in $42 \%$ of the patients. In our study, median HAQ was 0.13 (0; 0.8 ), with the worst functional outcome reported in RF positive polyarticular JIA. Only $8.7 \%$ of the patients had severe disability. Tollisen et al recently found even a lower percentage $(3 \%)$ of patients with severe disability at 30 -year follow-up. ${ }^{5}$

After adjustment for disease duration, we found less disability in patients with JIA when compared with patients with adult-onset rheumatic diseases. Studies comparing functional disability between adult patients with JIA with RA or SpA cohorts are scarce. To our knowledge there are only two studies evaluating physical disability in adult JIA and RA. ${ }^{35}$ Both studies, one from the pre-biological era and the other examining the differences between adult JIA and RA in the biologics era, found also better physical function in JIA than in patients with RA. In another study, 135 juvenile patients with AS were compared with 135 patients with adult-onset AS. ${ }^{37}$ The authors reported that functional impairment and disability were less marked in juvenile AS compared with adult-onset AS. In a more recent study also comparing juvenile and adult-onset AS, Stone et al found that juvenile patients with AS suffered more functional impairment compared with patients with adult-onset AS. ${ }^{38}$ However, the differences regarding the population selected and the measurements used to evaluate disability may account for the discrepancy in reported outcomes between studies.

This is the first study comparing depression and anxiety symptoms levels between JIA categories in adults and with adult-onset rheumatic diseases cohorts. We did not find differences among different JIA categories or between polyarticular patients with JIA and RA but patients with ERA had better results when compared with SpA, after adjustment for disease activity. Regarding depression and anxiety symptoms there are only studies comparing results in adult patients with JIA to the general population and with contradictory findings. Barth et al found 
significantly higher rates of anxiety/depression in JIA adults compared with healthy adults. ${ }^{10}$ In contrast, Raab et al found that only $4.9 \%$ of the adults with JIA selfreported depression, significantly fewer compared with the general population. ${ }^{39}$ We found a similar percentage $(4.8 \%)$ of adult patients with JIA who showed symptoms of depression and a higher number of patients with anxiety symptoms $(10.5 \%)$. These results are in line with the ones found among the adult Portuguese population with rheumatic and musculoskeletal diseases (RMDs) in a national health-survey conducted to estimate the national prevalence of RMDs. ${ }^{12}$ When the subjects with and without RMDs regarding mental distress symptoms were compared, Branco et al found a significantly higher proportion of patients with RMD with anxiety symptoms but not with depressive symptoms, with a prevalence of $16.7 \%$ for anxiety and $8.3 \%$ for depression. In this population-based study, SpA was the only RMD associated with anxiety symptoms, which could help to explain our worse results in SpA when compared with patients with ERA.

In our study fatigue symptoms were also worse in adult-onset diseases than in JIA and when JIA categories were compared, patients with ERA were the ones with less fatigue reports. Fatigue symptoms were shown to predict lower physical HRQoL at long-term in patients with JIA ${ }^{5}$ and to be more common in adults with JIA when compared with healthy controls. ${ }^{40}$ However, there are no other studies comparing long-term fatigue outcomes between JIA categories or between adult patients with JIA and adult-onset rheumatic diseases.

PROs such as HRQoL have been found to vary across different JIA categories in previous studies, with persistent oligoarticular JIA having better outcomes when compared with other JIA categories. ${ }^{35} 4142$ In our study we found that persistent oligoarthritis and patients with ERA had better scores in EQ5D and in the physical component of SF-36, regarding physical function, role limitations due to physical problems and intensity and the discomfort caused by pain, than other categories of JIA. This difference was significant when compared with patients with undifferentiated arthritis who had the worst scores in all these domains. This was also true for the social functioning domain of the mental component of SF-36 in which patients with undifferentiated arthritis had worst scores when compared with all other categories. These results could be explained by the fact that these patients classified as having undifferentiated arthritis JIA were the ones with late disease onset and late diagnosis, were older than patients from other categories and had longer disease duration. In our previous study with a similar cohort we showed that $50 \%$ of undifferentiated arthritis adult patients with JIA fulfilled criteria for RA, ${ }^{4}$ which could also help to explain these results.

Several studies analysing adult patients with JIA reported poorer physical functioning and perception of their health and more bodily pain when compared with age and sex matched controls. ${ }^{3} 10404344$ However, no study so far compared HRQoL from adult patients with JIA to age and sex matched patients having adultonset rheumatic diseases as controls. We found that patients with JIA with polyarticular course had better HRQoL than control patients with RA, after adjustment for disease duration. This was true for the self-reported problems in EQ5D, perceived health trough VAS and all domains of SF-36. In patients with ERA, who were older at disease onset, despite having better scores than patients with SpA in all domains of HRQoL, the significance of these differences were lost, after adjustment for disease activity. Less comorbidities or greater resilience of a younger body and mind could be explanations for generally better results in PROs from patients with JIA when compared with patients with RA and adult-onset SpA.

Our study has some limitations. First its cross-sectional design may not accurately estimate the evolution over time of functional status, mental health symptoms, fatigue and HRQoL in patients with JIA. As this is a long-term study the effect of different treatment strategies likely had also impact on some of these outcomes. In adult patients with ERA/SpA functional status would be measured in a more accurate way if we had used BASFI (Bath Ankylosing Spondylitis Functional Index) instead of HAQ. However, none of the instruments are validated in patients with ERA JIA. Additionally, selection bias of the registry may over-represent more severe cases and some categories of JIA, like the ones with polyarticular involvement, as many patients in remission could have been lost for follow-up and patients with milder disease could have been less motivated to be enrolled and complete questionnaires. In fact, not every patient included in the study had completed all PROs at the last visit registered, which led to missing data that could have influenced the results. Information on uveitis and joint replacement was not included due to missing data. Therefore, their role in the PROs results cannot be analysed.

This study has also several strengths, as the long follow-up and the use of both EQ5D and SF-36 to assess the HRQoL, which increased the consistency of the results regarding this outcome. It is also the first longterm study to compare outcomes regarding mental health symptoms and fatigue among JIA categories and mental health symptoms, fatigue and HRQoL in adult patients with JIA with age and sex matched patients with adult-onset rheumatic diseases.

In conclusion, our results document that persistent oligoarticular JIA and ERA are the categories with better HRQoL, namely in its physical component. Anxiety symptoms were more common than depression in patients with JIA, with similar results among different JIA categories. Adult patients with JIA with polyarticular course have less disability, fatigue and better HRQoL when compared with patients with RA but with similar frequency of anxiety and depression symptoms. 
Patients with ERA had less disability, less depression and anxiety symptoms and less fatigue symptoms than patients with SpA.

Overall adult polyarticular and ERA JIA have lower impact on function and on several quality of life-related aspects than RA and SpA.

\author{
Author affiliations \\ ${ }^{1}$ Rheumatology Department and Pediatric Rheumatology Unit, Centro Hospitalar \\ Universitário Lisboa Norte EPE, Lisboa, Portugal \\ ${ }^{2}$ Faculdade de Medicina, Universidade de Lisboa Instituto de Medicina Molecular, \\ Lisboa, Portugal \\ ${ }^{3}$ Centre for Chronic Diseases (CEDOC), CHRC Campus Nova Medical School, Lisboa, \\ Portugal \\ ${ }^{4}$ Portuguese Society of Rheumatology, Lisboa, Portugal \\ ${ }^{5}$ Young Adult and Pediatric Rheumatology Unit, Centro Hospitalar Universitario de \\ Sao Joao, Porto, Portugal \\ ${ }^{6}$ Rheumatology, Centro Hospitalar e Universitário de Coimbra EPE, Coimbra, \\ Portugal \\ ${ }^{7}$ Rheumatology, Unidade Local de Saude do Alto Minho EPE, Viana do Castelo, \\ Portugal \\ ${ }^{8}$ Rheumatology, Hospital Garcia de Orta EPE, Almada, Portugal \\ ${ }^{9}$ Rheumatology, Hospital do Divino Espírito Santo, São Miguel, Ponta Delgada, \\ Portugal \\ ${ }^{10}$ Rheumatology, Centro Hospitalar de Lisboa Ocidental EPE, Lisboa, Portugal \\ ${ }^{11}$ Rheumatology, Centro Hospitalar Universitário do Algarve, Faro, Portugal \\ ${ }^{12}$ Rheumatology, Centro Hospitalar do Baixo Vouga EPE, Aveiro, Portugal \\ ${ }^{13}$ Rheumatology, Hospital Dr. Nélio Mendonça, Funchal, Madeira, Portugal \\ ${ }^{14}$ Instituto Português de Reumatologia, Lisboa, Portugal
}

Acknowledgements This study would not have been possible without the collaboration of numerous clinicians, patients and their parents.

Collaborators None declared.

Contributors All authors contributed to the drafting, writing, editing and review of the manuscript. F. Oliveira Ramosaccepts full responsibility for the finished work and/or the conduct of the study, had access to the data, and controlled the decision to publish.

Funding The authors have not declared a specific grant for this research from any funding agency in the public, commercial or not-for-profit sectors.

Competing interests None declared.

Patient consent for publication Not applicable.

Provenance and peer review Not commissioned; externally peer reviewed.

Data availability statement All data relevant to the study are included in the article. Deidentified participant data.

Open access This is an open access article distributed in accordance with the Creative Commons Attribution Non Commercial (CC BY-NC 4.0) license, which permits others to distribute, remix, adapt, build upon this work non-commercially, and license their derivative works on different terms, provided the original work is properly cited, appropriate credit is given, any changes made indicated, and the use is non-commercial. See: http://creativecommons.org/licenses/by-nc/4.0/.

ORCID iDs

Filipa Oliveira Ramos http://orcid.org/0000-0001-7132-8909

Maria Jose Santos http://orcid.org/0000-0002-7946-1365

\section{REFERENCES}

1 Petty RE, Southwood TR, Manners P, et al. International League of associations for rheumatology classification of juvenile idiopathic arthritis: second revision, Edmonton, 2001. J Rheumatol 2004;31:390-2.

2 Zak M, Pedersen FK. Juvenile chronic arthritis into adulthood: a long-term follow-up study. Rheumatology 2000;39:198-204.

3 Foster HE, Marshall N, Myers A, et al. Outcome in adults with juvenile idiopathic arthritis: a quality of life study. Arthritis Rheum 2003;48:767-75

4 Oliveira-Ramos F, Eusébio M, M Martins F, et al. Juvenile idiopathic arthritis in adulthood: fulfilment of classification criteria for adult rheumatic diseases, long-term outcomes and predictors of inactive disease, functional status and damage. RMD Open 2016;2:e000304.

5 Tollisen A, Selvaag AM, Aulie HA, et al. Physical functioning, pain, and health-related quality of life in adults with juvenile idiopathic arthritis: a longitudinal 30-year followup study. Arthritis Care Res 2018;70:741-9.

6 Glerup M, Rypdal V, Arnstad ED, et al. Long-term outcomes in juvenile idiopathic arthritis: eighteen years of follow-up in the population-based Nordic juvenile idiopathic arthritis cohort. Arthritis Care Res 2020;72:507-16.

7 Rypdal V, Arnstad ED, Aalto K, et al. Predicting unfavorable longterm outcome in juvenile idiopathic arthritis: results from the Nordic cohort study. Arthritis Res Ther 2018;20:91.

8 Fair DC, Rodriguez M, Knight AM, et al. Depression and anxiety in patients with juvenile idiopathic arthritis: current insights and impact on quality of life, a systematic review. Open Access Rheumatol 2019;11:237-52.

9 Deshpande PR, Rajan S, Sudeepthi BL, et al. Patient-reported outcomes: a new era in clinical research. Perspect Clin Res 2011;2:137-44

10 Barth S, Haas J-P, Schlichtiger J, et al. Long-term healthrelated quality of life in German patients with juvenile idiopathic arthritis in comparison to German general population. PLOS One 2016;11:e0153267.

11 Laas K, Roine R, Räsänen P, et al. Health-related quality of life in patients with common rheumatic diseases referred to a university clinic. Rheumatol Int 2009;29:267-73.

12 Branco JC, Rodrigues AM, Gouveia N, et al. Prevalence of rheumatic and musculoskeletal diseases and their impact on health-related quality of life, physical function and mental health in Portugal: results from epireumapt- a national health survey. RMD Open 2016;2:e000166.

13 Relas H, Kosola S. Acceptable quality of life and low disease activity achievable among transition phase patients with rheumatic disease. Clin Rheumatol 2019;38:785-91.

14 Packham JC, Hall MA, Pimm TJ. Long-term follow-up of 246 adults with juvenile idiopathic arthritis: predictive factors for mood and pain. Rheumatology 2002;41:1444-9.

15 Canhão H, Faustino A, Martins F. Rheumatic diseases portuguese register board coordination, Portuguese Society of Rheumatology. Reuma.pt - the rheumatic diseases portuguese register. Acta Reumatologica Portuguesa 2011;36:45-56.

16 Reuma.pt. Available: http://reuma.pt/pt_PT/Default.aspx [Accessed 07 Oct 2020].

17 Consolaro A, Ruperto N, Bazso A, et al. Development and validation of a composite disease activity score for juvenile idiopathic arthritis. Arthritis Rheum 2009;61:658-66.

18 Smolen JS, Breedveld FC, Eberl G, et al. Validity and reliability of the twenty-eight-joint count for the assessment of rheumatoid arthritis activity. Arthritis Rheum 1995;38:38-43.

19 van Gestel AM, Prevoo ML, van 't Hof MA, et al. Development and validation of the European League against rheumatism response criteria for rheumatoid arthritis. Comparison with the preliminary American College of rheumatology and the world health Organization/International League against rheumatism criteria. Arthritis Rheum 1996;39:34-40.

20 Fransen J, Creemers MCW, Van Riel PLCM. Remission in rheumatoid arthritis: agreement of the disease activity score (DAS28) with the Ara preliminary remission criteria. Rheumatology 2004:43:1252-5.

21 Prevoo ML, van Gestel AM, van T Hof MA, et al. Remission in a prospective study of patients with rheumatoid arthritis. American rheumatism association preliminary remission criteria in relation to the disease activity score. Br J Rheumatol 1996;35:1101-5.

22 Heimans L, Akdemir G, Boer KVCW-de, et al. Two-year results of disease activity score (DAS)-remission-steered treatment strategies aiming at drug-free remission in early arthritis patients (the IMPROVED-study). Arthritis Res Ther 2016;18:23.

23 van der Heijde D, Lie E, Kvien TK, et al. ASDAS, a highly discriminatory ASAS-endorsed disease activity score in patients with ankylosing spondylitis. Ann Rheum Dis 2009;68:1811-8.

24 Wallace CA, Ruperto N, Giannini E, et al. Preliminary criteria for clinical remission for select categories of juvenile idiopathic arthritis. $J$ Rheumatol 2004;31:2290-4.

25 Viola S, Felici E, Magni-Manzoni S, et al. Development and validation of a clinical index for assessment of long-term damage in juvenile idiopathic arthritis. Arthritis Rheum 2005;52:2092-102.

26 Fries JF, Spitz P, Kraines RG, et al. Measurement of patient outcome in arthritis. Arthritis Rheum 1980;23:137-45.

27 Ruperto N, Ravelli A, Levinson JE, et al. Long-term health outcomes and quality of life in American and Italian inception cohorts of 
patients with juvenile rheumatoid arthritis. II. early predictors of outcome. J Rheumatol 1997;24:952-8.

28 Ferreira PL, Ferreira LN, Pereira LN. [Contribution for the validation of the Portuguese version of EQ-5D]. Acta Med Port 2013;26:664-75

29 Ferreira PL. [Development of the Portuguese version of MOS SF-36. Part II --Validation tests]. Acta Med Port 2000;13:119-27.

$30 \mathrm{FACIT} \mathrm{Home.} \mathrm{FACIT-Fatigue} \mathrm{languages.} \mathrm{Available:} \mathrm{https://www.facit.}$ org/measures/FACIT-Fatigue [Accessed 09 Oct 2020].

31 Pais-Ribeiro J, Silva I, Ferreira T, et al. Validation study of a Portuguese version of the hospital anxiety and depression scale. Psychol Health Med 2007;12:225-37.

32 Matcham F, Rayner L, Steer S, et al. The prevalence of depression in rheumatoid arthritis: a systematic review and meta-analysis. Rheumatology 2013;52:2136-48.

33 Selvaag AM, Aulie HA, Lilleby V, et al. Disease progression into adulthood and predictors of long-term active disease in juvenile idiopathic arthritis. Ann Rheum Dis 2016;75:190-5.

34 Berthold E, Månsson B, Kahn R. Outcome in juvenile idiopathic arthritis: a population-based study from Sweden. Arthritis Res Ther 2019;21:218

35 Matsumoto T, Matsui T, Hirano F, et al. Disease activity, treatment and long-term prognosis of adult juvenile idiopathic arthritis patients compared with rheumatoid arthritis patients. Mod Rheumatol 2020;30:78-84.

36 Koivuniemi R, Leirisalo-Repo M. Juvenile chronic arthritis in adult life: a study of long-term outcome in patients with juvenile chronic arthritis or adult rheumatoid arthritis. Clin Rheumatol 1999;18:220-6.
37 Calin A, Elswood J. The natural history of juvenile-onset ankylosing spondylitis: a 24-year retrospective case-control study. $\mathrm{Br} \mathrm{J}$ Rheumatol 1988;27:91-3.

38 Stone M, Warren RW, Bruckel J, et al. Juvenile-onset ankylosing spondylitis is associated with worse functional outcomes than adult-onset ankylosing spondylitis. Arthritis Rheum 2005;53:445-51.

39 Raab A, Sengler C, Niewerth M, et al. Comorbidity profiles among adult patients with juvenile idiopathic arthritis: results of a biologic register. Clin Exp Rheumatol 2013;31:796-802.

40 Peterson LS, Mason T, Nelson AM, et al. Psychosocial outcomes and health status of adults who have had juvenile rheumatoid arthritis: a controlled, population-based study. Arthritis Rheum 1997;40:2235-40.

41 Arkela-Kautiainen M, Haapasaari J, Kautiainen $\mathrm{H}$, et al. Favourable social functioning and health related quality of life of patients with JIA in early adulthood. Ann Rheum Dis 2005;64:875-80.

42 Minden K, Niewerth M, Listing J, et al. Long-term outcome in patients with juvenile idiopathic arthritis. Arthritis Rheum 2002;46:2392-401.

43 Ostile IL, Johansson I, Aasland A, et al. Self-rated physical and psychosocial health in a cohort of young adults with juvenile idiopathic arthritis. Scand J Rheumatol 2010;39:318-25.

44 Tollisen A, Selvaag AM, Aasland A, et al. Longitudinal health status from early disease to adulthood and associated prognostic factors in juvenile idiopathic arthritis. J Rheumatol 2019;46:1335-44. 